ISSN 2236-0859

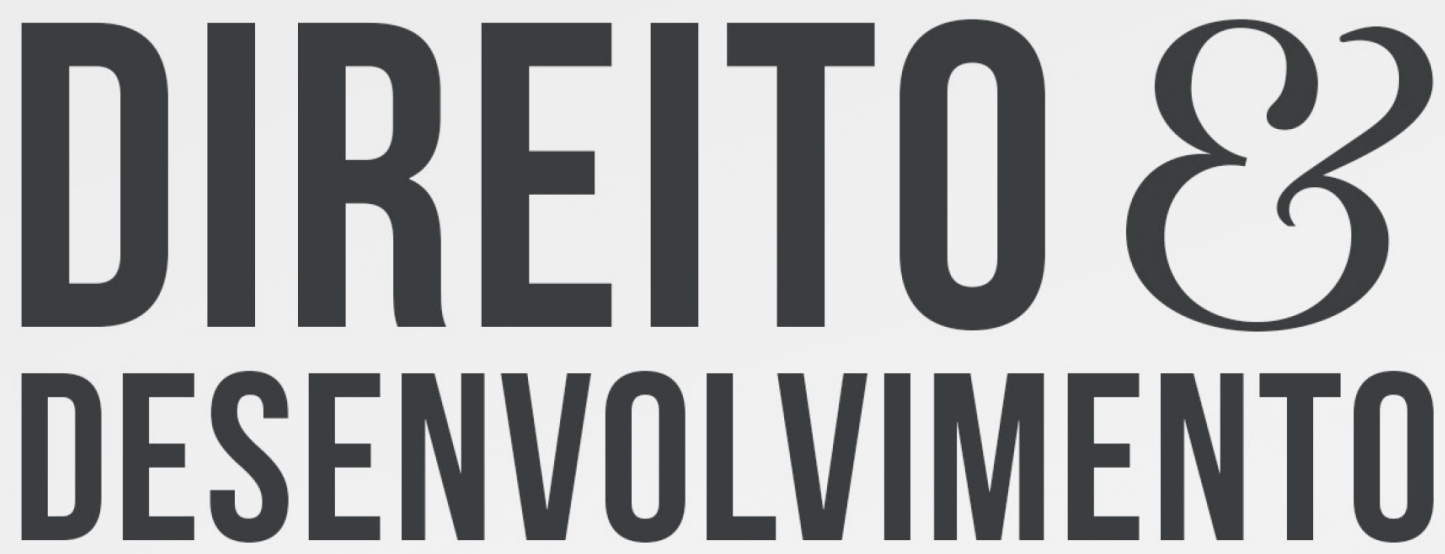

REVISTA DO PROGRAMA DE PÓS-GRADUAÇ̃̃O EM DIREITO MESTRADO EM DIREITO E DESENVOLVIMENTO SUSTENTÁVEL

REGULACÃO DAS FAKE NEWS: UM DLEMA DIANTE DO DIREITO À LIBERDADE DE EXPRESSÃO

WELLINGTON ANTONIOBALDISSERA

VINICIUS BORGES FORTES 


\title{
REGULAÇÃO DAS FAKE NEWS: UM DILEMA DIANTE DO DIREITO À LIBERDADE DE EXPRESSÃO
}

\section{REGULATION OF FAKE NEWS: A DILEMMA IN THE FACE OF THE RIGHT TO FREEDOM OF EXPRESSION}

Recebido: 09/02/2019

Aprovado: 21/07/2021
Wellington Antonio Baldissera ${ }^{1}$

Vinícius Borges Fortes ${ }^{2}$

\section{RESUMO:}

As mentiras sempre existiram, mas com a internet, a velocidade de propagação aumentou de forma exponencial, colocando em evidência as Fake news. Diante da relevância e da influência que esta prática pode causar na sociedade, nesse estudo será abordada a necessidade do Estado estabelecer um controle sobre a divulgação de informações falsas, diante dos malefícios que podem causar. A dúvida que buscará ser esclarecida é sobre quais são as dificuldades existentes para se estabelecer uma regulação sobre a propagação de fake news no Brasil. O objetivo geral deste estudo é apresentar um panorama sobre a possibilidade de ser instituída pelo Estado, uma forma de regulação em face das fake ews, sendo o melhor meio para ser possível a instituição desta medida uma regulação repressiva, combatendo a desinformação, com mais informação. O método utilizado nesta pesquisa é o monográfico e a técnica de pesquisa é a bibliográfica.

Palavras-chave: Informações falsas. Agências de fact-chaking. Agências reguladoras. Redes sociais. Desinformação.

\begin{abstract}
:
The lies have always existed, but with the internet, the speed of propagation has increased exponentially, putting in evidence the Fake news. Given the relevance and influence that this practice can cause in society, this study will address the need for the State to establish a control over the dissemination of false information, given the harm they can cause. The doubt that will seek to be clarified is on what are the difficulties to establish a regulation on the propagation of fake news in Brazil. The general objective of this study is to present a panorama on the possibility of being instituted by the State, a form of regulation in the face of Fake news, being the best way to be possible the institution of this measure a repressive regulation, combating misinformation, with more information. The method used in this research is the monographic one and the research technique is the bibliographical.
\end{abstract}

Keywords: False information. Fact-chaking agencies. Regulatory agencies. Social networks. Misinformation.

1 Mestrando em Direito pela Faculdade Meridional - IMED com bolsa na modalidade taxa CAPES/PROSUP; Especialista em Direito Administrativo pelo Complexo Educacional Renato Saraiva (CERS); Assessor Jurídico na área de Direito Público; Advogado. Email: 2 Pós-Doutor em Direito pela VUB - Vrije Universiteit Brussel (Bélgica); Doutor em Direito pela UNESA/RJ; Mestre em Direito pela UCS/ RS; Coordenador e Professor Permanente do Programa de Pós-Graduação Stricto Sensu - Mestrado em Direito da IMED - Faculdade Meridional; Pesquisador do Grupo de Pesquisa em Direito e Desenvolvimento, certificado pela IMED e pelo CNPq; Pesquisador visitante na Universidad de Zaragoza (Espanha) (2014-2015); Professor visitante na VUB - Vrije Universiteit Brussel (Bélgica), no LSTS - Law, Science, Technology and Society Research Group no âmbito do projeto Brussels Privacy Hub (2016); Advogado; Endereço eletrônico: vinicius.fortes@imed.edu.br 


\section{INTRODUÇÃO}

A informação tem um papel preponderante na sociedade. As pessoas estão cada vez mais sedentas por conhecimento e por notícias sobre os mais variados temas, e o meio mais utilizado para saciar essa busca é a internet, colocando em segundo plano mídias tradicionais como o rádio, a televisão, os jornais e as revistas impressas.

Graças a essa nova perspectiva, atingiu-se um elevado patamar de globalização e informatização, em poucos segundos, na tela de um celular smartphone, é possível saber, no Brasil, qualquer acontecimento ocorrido no Japão, mesmo há milhares de quilômetros de distância. Em face disso, algumas questões merecem ser refletidas: com essa rapidez e facilidade de se obter informações através da internet, podemos confiar em tudo que lemos ou vemos? E como é possível controlar a fonte e a veracidade das notícias veiculadas na internet?

Todavia, é notório que não existe um controle efetivo no Brasil sobre a reprodução das fake news, isso se deve aos mais variados fatores, principalmente a dificuldade de ser estabelecido um conceito preciso sobre o que são e sobre como exercer uma regulação sem que exista um abuso no direito à liberdade de expressão, assim, o problema que se pretende responder com essa pesquisa é: quais são as dificuldades existentes para se estabelecer uma regulação sobre a propagação de fake news no Brasil?

Não é uma tarefa simples estabelecer um controle sobre a proliferação de fake news no Brasil, tanto diante dos conflitos entre direitos que podem decorrer dessa medida, como diante do grande número de cidadãos com acesso à internet, mas a hipótese que se pretende confirmar ao longo desta pesquisa é que a regulação das fake news pelo Estado é essencial para combater os malefícios que podem apresentar para a sociedade brasileira.

O objetivo geral do estudo em tela é apresentar um panorama sobre a possibilidade de ser instituída pelo Estado, uma forma de regulação em face das Fake news. Os objetivos específicos são: (i) conceituar o que é regulação e agências reguladoras; (ii) explicar sobre a regulação da internet no Brasil; (iii) definir as Fake news; (iv) explicar quais são as dificuldade de se estabelecer uma regulação estatal sobre as Fake news; (v) apresentar meios para combater a propagação das Fake news.

O método de abordagem utilizado, neste trabalho, foi o hipotético-dedutivo; o método de procedimento foi o comparativo; o tipo de pesquisa tem natureza qualitativo-exploratória, e as técnicas de pesquisa utilizado foi a pesquisa bibliográfica.

\section{ASPECTOS GERAIS DA REGULAÇÃO E DAS AGÊNCIAS REGULADORAS}

Em síntese, a regulação pode ser entendida como um modelo de gestão específico definido, para controlar ou gerenciar determinada questão que seria de responsabilidade do governo do Estado, seja alguma área da economia, da saúde, das novas tecnologias ou incontáveis outras. No Brasil, está intrinsicamente ligada com a ideia da Administração Pública, diante da existência de inúmeras agências regulatórias, e também, a sua utilização é uma medida que está relacionada diretamente com o princípio da eficiência do Estado.

Objetivando a finalidade específica de alcançar instrumentos de elevação e proteção da dignidade da pessoa humana, uma das funções do Estado é a de formular políticas públicas, por meio de dois tipos de ações que devem ser realizadas em conjunto para chegar ao propósito final, que seria regular a competividade dos mercados e promover o bem comum da sociedade. (LEAL, 2014). 
Essas medidas devem prezar pelo princípio da eficiência da Administração Pública, devendo o Estado, sempre buscar a melhor alternativa que resulte na menor onerosidade possível, para tratar das mais diversas demandas da sociedade. Este princípio pode ser conceituado da seguinte forma:

\begin{abstract}
Assim, princípio da eficiência é o que impõe à administração pública direta e indireta e a seus agentes a persecução do bem comum, por meio do exercício de suas competências de forma imparcial, neutra, transparente, participativa, eficaz, sem burocracia e sempre em busca da qualidade, rimando pela adoção dos critérios legais e morais necessários para melhor utilização possível dos recursos públicos, de maneira a evitarem-se desperdícios e garantir-se maior rentabilidade social. (MORAES, 1999, p. 30).
\end{abstract}

Diante do princípio supracitado, surge a ideia da regulação dos setores ou de determinadas questões de uma nação, considerando a dificuldade para o governo de um Estado conseguir atender todas as demandas com a devida atenção. O Estado possui um poder regulador, o qual lhe permite fiscalizar e controlar os serviços prestados por ele e por terceiros, inclusive com relação à economia, podendo optar pela criação de agências reguladoras responsáveis por serviços essenciais à sociedade, sendo um meio mais eficiente de realizar suas atribuições. Assim, convém expor o conceito do que seria a regulação:

[...]neste sentido, por regulação a atividade estatal mediante a qual o Estado, por meio de intervenção direta ou indireta, condiciona, restringe, normatiza ou incentiva a atividade econômica de modo a preservar a sua existência, assegurar o seu equilíbrio interno ou atingir determinados objetivos públicos como a proteção de hiposuficiências ou a consagração de políticas públicas. (NETO, 2002, p.14).

Em complemento ao conceito acima, vale frisar que "do ponto de vista político e econômico, regulação governamental significa a imposição de regras à ação de atores privados (eventualmente estatais), que atuam em determinados mercados. Essas regras podem ser determinadas por meio de atos normativos, sanções, supervisão ou, eventualmente, pela própria inação." (IDEC, 2011, p.11).

Na Constituição Federal de 1988, em seu art. 174, caput, é reconhecido ao Estado, o papel de "agente normativo e regulador da atividade econômica", estando assim, garantido pela legislação o poder regulador do Estado, não havendo margens para questionamentos quanto a isso.

Além de ser um meio mais eficiente para administrar determinados setores, a regulação surge diante da obscuridade das leis emitidas pelo Poder Legislativo, decorre da ambiguidade das normas de conduta que são necessárias para governar a vida econômica e social. (GUERRA, 2014).

Os principais objetivos que se busca por meio da regulação estatal de alguma atividade, são definir tarifas justas e razoáveis de energia e transporte, promover condições razoáveis à proteção da vida, saúde e segurança do trabalhador, a redução de custos de tomada de decisão e necessidade de assegurar a credibilidade dos compromissos de longo prazo dos contratos, além dos prazos políticos. (PECI, 2014, p. 50/51).

No nosso país existem o6 (seis) modelos de regulação que são utilizados, havendo a direta, que é a exercida diretamente pelos ministérios e secretarias; as autarquias comuns, que são vinculadas, porém não subordinadas aos ministérios, todavia, os agentes são nomeados pelos ministros e são cargos de livre exoneração; as agências executivas, que a única existente seria o Inmetro (Instituto Nacional de Metrologia, Qualidade e Tecnologia), que é uma autarquia com maior autonomia que as demais; as autarquias especiais, que são o CADE (Conselho Administrativo de Defesa Econômica) e o CVM (Comissão de Valores Mobiliários). Essas 
entidades não são subordinadas ao poder público central; possuem órgãos de direção colegiados, em que cada diretor recebe um mandato. Detêm autonomia administrativa, financeira e independência decisória; os conselhos profissionais, como por exemplo, o Conselho Regional de Medicina; ainda há a autorregulação exercida pela Ordem dos Advogados do Brasil, como entidade sui generis, ou seja, diante de sua natureza única. (GUERRA, 2014, p. 368-369)

Executar com perfeição a proposta apresentada pela regulação, não é uma tarefa simples, existindo várias nuances que devem ser observadas para que venha a ser realmente efetiva, devendo o Estado tomar certos cuidados, como se percebe neste comentário:

A noção de atividade regulatória numa perspectiva de "mediação ativa de interesses" envolve uma dupla atividade estatal. De um lado, o regulador tem de arbitrar interesses de atores sociais e econômicos fortes, como ocorre no equacionamento de conflitos envolvendo compartilhamento de infra-estruturas ou interconexão de redes de suporte a serviços essenciais. Doutro bordo, cumpre ao regulador induzir ou coordenar as atividades em cada segmento específico com vistas a proteger e implementar interesses de atores hipossuficientes. É o que tem lugar na defesa dos consumidores ou no atendimento de políticas públicas (universalização de serviços, redução de desigualdades sociais ou regionais, entre outros). (NETO, 2002, p. 17).

A regulação possui um caráter social, pois como já dito anteriormente, ela deve buscar o bem estar dos cidadãos, devendo assim, buscar e garantir a acessibilidade e a qualidade dos serviços públicos para toda a coletividade. Em face disso, cabe exibir a constatação de Sundfeld (2014, p.119):

Sem adentrar nas minúcias da lei, a verdade é que, com ela, pretende- se a universalização total do serviço de saneamento básico. Para alcançar essa meta, optou-se por obrigar os titulares do serviço a criarem agências reguladoras para o setor, de modo a impor deveres aos prestadores e a cria direitos para os consumidores e para os não consumidores, que possuem direito à expansão do serviço.

Com a menção, no trecho acima, sobre as agências reguladoras, convém apresentar o que seriam esses órgãos, que são pessoas jurídicas de Direito Público interno, normalmente são autarquias da administração indireta e, também possuem um regime jurídico especial, sendo interessante explanar algumas especificidades sobre o assunto em tela:

Paralelamente à disciplina legislativa e regulamentar, que reúne as normas e critérios ordenadores de cada um dos setores objeto de concessão de serviços públicos ao empresário privado, surgem os organismos constituídos pelo Poder Público, para normatizar, aplicar as normas legais, regulamentares e contratuais da atividade sob sua tutela, outorgar e rescindir os contratos de concessão, bem como fiscalizar os serviços concedidos, além de funcionar, em muitos casos, como instância decisória dos conflitos entre as empresas concessionárias e os usuários. (WALD; MORAES, 1999, p. 145).

De uma maneira bem sucinta, o conceito de agências reguladoras pode ser entendido, como coloca Grotti, "em sentido amplo, no direito brasileiro, agência reguladora é qualquer órgão da Administração Direta ou Indireta com função de regular a matéria específica que lhe está afeta." (GROTTI, 2004, p. 70).

Seu surgimento ocorreu, principalmente, pela enorme privatização das empresas estatais em nosso país, entre o final do século XX e início deste século. Considerando que o Estado ainda era responsável por alguns dos serviços que vieram a ser privatizados, acabou por criar agências reguladoras para estabelecer normas e diretrizes, além de fiscalizar a prestação de serviços por particulares. 
Portanto, em um primeiro momento, as agências reguladoras surgiram em decorrência da desestatização de serviços públicos e exploração de determinadas atividades econômicas. No entanto, hoje elas não se limitam a ser um instrumento de desestatização, mas também regulam atividades da livre iniciativa privada com especial sensibilidade para a coletividade, como ocorre no modelo americano. (SAMPAIO, 2014, p. 318-319).

Existe a ressalva de que as atividades em que o Estado desempenha em conjunto com a iniciativa privada, também estão sujeitas às normas das agências reguladoras, como exemplo, é possível citar a educação, onde há existência de universidades tanto públicas, quanto particulares. No caso, uma autarquia do Estado, criada pelo próprio Estado, deve fiscalizar a atuação da iniciativa privada e, também, do Estado, na área que for de sua incumbência.

Ao estabelecer as normas para a criação das agências reguladoras, o legislador brasileiro escolheu por definir que, atuariam como autarquias, pessoas jurídicas de direito público, que já estavam presentes dentro de nossa legislação, todavia, com o objetivo de diferenciá-las das autarquias que não possuíam poder de regulação, concedeu a elas, a qualidade de possuir um regime especial. Sobre este regime jurídico, Celso Antônio Bandeira de Mello (2013, p. 178), diz:

(...) Anotou-se que as "agências reguladoras" são autarquias "sob regime especial". Afinal, em que consistiriam seus regimes especiais? (...) Assim, a lei da ANATEL, em seu art. 8o, $\S 2^{2}$, apresenta como seus traços especificadores “independência administrativa, ausência de subordinação hierárquica, mandato fixo e estabilidade de seus dirigentes e autonomia financeira”. A lei da ANS, no art. 1º, parágrafo único, aponta como caracterizadores de tal regime "autonomia administrativa, financeira, patrimonial e de gestão de recursos humanos, autonomia nas suas decisões técnicas e mandato fixo de seus dirigentes"; a lei da ANVISA (dantes denominada ANVS), no seu art. $3^{\circ}$, parágrafo único, aponta como caracterizadores de tal regime "independência administrativa, a estabilidade de seus dirigentes e a autonomia financeira" e a lei criadora da ANTT e da ANTAQ indicam, no art. $21, \S 2^{\circ}$, que o regime autárquico especial é caracterizado pela "independência administrativa, autonomia financeira e funcional e mandato fixo de seus dirigentes".

No entanto, o próprio Mello (2013), menciona em sua obra que esta definição de regime especial, não implica em grandes diferenças do regime tradicional das outras autarquias, uma vez que todas as características ditas acima, são inerentes a todas as autarquias, o que muda é a intensidade em que essas características se apresentam.

Sobre a atuação das agências reguladoras no Brasil, cabem alguns apontamentos:

No Brasil, o sistema financeiro foi o primeiro a ganhar um órgão regulador bemorganizado. O Banco Central - a agência reguladora de maior tradição no Brasil - exerce um poder regulador exemplar, de modo a influenciar as práticas das demais agências existentes. E foi justamente em relação ao Banco Central, sobretudo ao longo das décadas de 1960 e 1970, que primeiro se discutiu sobre a validade ou a invalidade de um poder normativo exercido pela administração pública. Hoje em dia, ao contrário, as agências reguladoras editam normas sem que ninguém considere isso espantoso, apesar das críticas, inclusive no campo da constitucionalidade. (SUNDFELD, 2014, p. 120).

As agências reguladoras possuem um papel de grande importância na estrutura da sociedade brasileira atualmente. Assim, é difícil explicar todas as características delas, com precisão, em poucas páginas, mas pelo que foi exposto, fica clara a relevância que possuem na administração do nosso país.

As principais agências reguladoras existentes no Brasil, segundo informado no próprio site do governo brasileiro, em esfera federal são: Agência Nacional de Energia Elétrica (Aneel), Agência Nacional de Telecomunicações (Anatel), Agência Nacional do Petróleo (ANP), Agência Nacional de Vigilância Sanitária (Anvisa), Agência Nacional de Saúde Suplementar (ANS), 
Agência Nacional de Águas (ANA), Agência Nacional de Transportes Terrestres (ANTT) e Agência Nacional de Transportes Aquaviários (Antaq), Agência Nacional do Cinema (Ancine), Agência Nacional de Aviação Civil (Anac) e o já mencionado Banco Central (Bacen).

Ainda, podem existir outros órgãos com funções reguladoras no âmbito estadual e municipal, sendo ligadas às respectivas esferas administrativas. Em qualquer dos níveis de organização do estado, elas dependem ou de uma secretaria ou de um ministério, de acordo com Peci (2014, p. 54):

Formalmente, estas dependem dos ministérios, os quais são responsáveis por formular políticas regulatórias. No entanto, ao longo dos anos, o corpo técnico das agências, o conhecimento especializado desses órgãos e o esvaziamento dos ministérios contribuíram para concentrar o processo de formulação e implementação de políticas regulatórias nas agências, abrindo espaço para questionamentos do modelo.

Normalmente, as agências reguladoras produzem as normas específicas sobre as matérias que lhe é competente, por meio de resoluções normativas, o que se relaciona com o que foi dito no início da pesquisa sobre a função da regulação em resolver as obscuridades existentes nas leis, ou até a omissão, considerando que as resoluções não necessitam de aprovação do poder legislativo, todavia, existe a possibilidade de existir regulação por meio de leis ou outros meios de direito público geral, mas as agências atuam por meio das resoluções.

Ainda existem outras possibilidades, por intermédio do direito administrativo, em sentido estrito, como os regulamentos administrativos, os contratos públicos, os processos administrativos e os atos administrativos.

\section{A REGULAÇÃO DA INTERNET NO BRASIL}

O mundo não é mais o mesmo que era por volta de $1970^{3}$, período onde a internet começou a dar os seus primeiros passos. $\mathrm{O}$ jeito de se comunicar, se relacionar com as pessoas, ler notícias, se divertir, trabalhar, enfim, a forma de viver, não é mais igual do que era no século passado.

Durante a longínqua década dos anos 6o, época em que The Beatles, Pink Floyd, The Rolling Stones e outras grandes bandas surgiram ${ }^{4}$, com suas músicas tocadas nas rádios do mundo todo, inclusive no Brasil, fazendo grande sucesso, que consegue ser mantido até os dias atuais. Durante os anos 6o, ouvir frequentemente determinado grupo ou uma música específica a única opção era adquirir os discos de vinil.

A partir dos anos 200o, vários cantores passaram a fazer muito sucesso, como por exemplo, Sean Kingston, Soulja Boy, Justin Bieber, Shawn Mendes, The Weeknd, mas chegaram ao status que possuem ,não devido, inicialmente às rádios, muito menos aos discos de vinil, que já se tornaram obsoletos, mas sim graças a internet e as mídias de compartilhamento, como SoundClick, Vine, MySpace, e principalmente, o YouTube, alguns nem atingindo grande representatividade com relação a venda de CDs, os sucessores dos discos de vinil 5 .

As músicas de qualquer um dos cantores citados acima, podem ser ouvidas a qualquer hora de forma gratuita, seja no YouTube, em streamings como o Spotyfy ou Deezer, ou em

3 Mais informações sobre o surgimento da internet em: SILVA, Werner Leonardo. Internet foi criada em 1969 com o nome de "Arpanet" nos EUA. Disponível em: https://www1.folha.uol.com.br/folha/cotidiano/ult95u34809.shtml. Acesso em o4 de fevereiro de 2019 .

4 Mais informações sobre o cenário musical dos anos 6o em: PRANDO, Alisson. Músicas dos Anos 6o: O Sucesso que Balançou o Mundo. Disponível em: https://www.uppermag.com/musicas-dos-anos-6o/ . Acesso em: 04 de fevereiro de 2019.

5 Outros exemplos de cantores e bandas descobertos na internet em: NATALO, Camila. 13 cantores e bandas que foram descobertos na internet. Disponível em: http://www.popcidade.com.br/2016/o2/18/13-cantores-e-bandas-que-foram-descobertos-na-internet/. Acesso em: 04 de fevereiro de 2019. 
várias outras mídias, é possível fazer o download delas para ouvirmos em grande parte dos aparelhos eletrônicos. Tudo isso, devido ao advento da internet, que mudou o jeito de ouvirmos músicas, das pessoas atingirem o sucesso, enfim, mudou quase tudo.

Essa relação da evolução do cenário musical, no decorrer dos anos, com a utilização da internet, é apenas um meio de demonstrar como a nossa sociedade evoluiu em torno dessa tecnologia e das inovações decorrentes.

Outro exemplo dessa evolução são as produções cinematográficas, que inicialmente, era necessário ir ao cinema para ver os filmes, após chegaram a TV, foram lançados os filmes em fita VHS, seguindo-se dos DVDs, havendo um sucesso imenso com as famosas locadoras de DVDs, e hoje a maioria dos filmes, são vistos on-line ou obtidos por meio de download, nem sempre de forma legal, ou por meio de streamings, como o NetFlix ${ }^{6}$.

Sobre essa nova faceta que passou a existir diante dos novos meios que surgiram, vale a menção deste comentário:

O uso das Tecnologias da Informação e Comunicação (TIC), sobretudo a Internet, expandiu-se para os mais variados meios. Atualmente, são verdadeiras ferramentas para angariar notícias, entretenimento, e até mesmo para fomentar o acesso a informações prestadas pela Administração Pública, bem como para a prática da democracia e cidadania eletrônicas. As TIC formam uma ampla rede de comunicação entre os usuários, transpondo barreiras territoriais, espaciais e temporais, além de fixar verdadeiras relações com os mais diversos sujeitos em escala global. (OLIVEIRA; BARROS; GOULART, 2016, p. 89).

Com as situações expostas, se percebe a rápida evolução da internet, desde o seu surgimento e como os mais diversos setores, indústrias e áreas existentes em nosso meio, se adaptaram à demanda que ela solicitava. Entretanto, um dos pilares que mantém as estruturas do mundo civilizado, não foi capaz de acompanhar essa veloz mutação, ou seja, o direito não é capaz de acompanhar a velocidade com que as demandas e conflitos decorrentes da internet suscitam.

Mesmo diante da grande importância que passou a ter, no Brasil, não foi criada nenhuma agência reguladora para tentar resolver os problemas que vieram junto com a popularização da internet. Na verdade, demorou algum tempo para que fossem estabelecidas leis específicas no Brasil, para tentar normatizar algumas das situações que vieram a ocorrer.

Vale a menção ao Projeto de Lei no 53, a qual havia sido aprovado inicialmente pelas duas câmaras do Congresso Nacional, que originou a atual Lei 13.709 de 14 de Agosto de 2018, previa a criação de uma agência reguladora para o controle e fiscalização dos dados pessoais dos cidadãos brasileiros na internet, todavia, o Presidente da República que sancionou esta lei, Michel Temer, acabou por vetar essa iniciativa, alegando que a mesma não poderia ser realizada por meio de iniciativa do poder legislativo, necessitando de uma lei específica para sua criação (BRASIL, 2018).

Com o que foi colocado no parágrafo acima, se denota que os legisladores brasileiros perceberam a necessidade da criação de ser estabelecido um controle sobre o que acontece no mundo virtual, diante da relevância que passou a ter, e da influência que exerce na vida dos usuários da internet. Em muitos casos, os crimes cometidos por meio da internet já são previstos ou enquadrados em outros pré-existentes no Código Penal Brasileiro.

Realmente, não é uma tarefa simples realizar a regulação da internet do Brasil, considerando que é extremamente difícil fiscalizar o que ocorre no mundo virtual, pois somente estabelecer as normas, sem que exista o devido controle sobre seu cumprimento, seria

6 Mais informações sobre a evolução dos meios de acesso de obras audiovisuais em: Do VHS ao streaming, conheça a evolução das tecnologias de armazenamento e compartilhamento de vídeo. Disponível em:http://www.olhardireto.com.br/noticias/exibir. asp?id=408271\&noticia=do-vhs-ao-streaming-conheca-a-evolucao-das-tecnologias-de-armazenamento-e-compartilhamento-devideo. Acesso em: 04 de fevereiro de 2019. 
não ter efetividade alguma. Além de que, seria necessário um alto investimento financeiro em aparelhos, softwares, capacitação e vários outros pontos que seriam necessários para ser efetiva essa sugestão.

Todavia, algumas medidas foram tomadas pelo Poder Legislativo do nosso país, considerando, que para o Poder Judiciário, já não era mais uma tarefa fácil resolver as demandas resultantes de conflitos cibernéticos, sem o auxílio de uma legislação sobre esse tema. No entanto, por mais que foram estabelecidas várias normas, é praticamente impossível conseguir abranger todos os fatos que podem vir a ocorrer na relação entre direito e internet.

Os primeiros passos foram dados, agora cabe aprimorar, e aumentar a abrangência destas leis que foram criadas. As leis mais notáveis que vieram a ser criadas foram a da Lei de Acesso à Informação (Lei no. 12.527/2011), a Lei de Crimes Informáticos (Lei no. 12/737/2012) e, se pode colocar como o destaque substancial dessas medidas que foram tomadas nos últimos anos, a instituição do Marco Civil da Internet (Lei no. 12.965/2014).

É válida a menção da Lei no 13.709 de 14 de Agosto de 2018, a qual normatiza com especificidade a proteção de dados pessoais no Brasil, já que este é um dos maiores problemas existentes da sociedade informatizada, tratando sobre a maioria dos pontos necessários para existir o mínimo de proteção das informações do cidadão brasileiro, protegendo-as, inclusive, contra a transferência para outros países e o uso indevido dos dados por empresas privadas.

Com relação a Lei do Acesso à Informação, de forma resumida, pode ser entendida desta forma:

\begin{abstract}
A Lei de Acesso à Informação determina que o tratamento das informações pessoais detidas por entidades e instituições nela abrangidas seja realizado de modo transparente, respeitando o direito fundamental à proteção da intimidade, da vida privada, da honra e da imagem das pessoas, o que, nos fundamentos defendidos nesta obra, corresponde à proteção do direito fundamental à privacidade. A lei impõe restrições substanciais de acesso a informações pessoais, como o acesso restrito às informações, pelo prazo máximo de cem anos, a agentes públicos autorizados, bem como a possibilidade de acesso ou divulgação a terceiros, mediante prévio consentimento do titular das informações, exceto nos casos previstos no regulamento. (FORTES, 2016, p. 118).
\end{abstract}

Sobre a chamada Lei de Crimes Informáticos, que foi vulgarmente denominada pelo povo como Lei Carolina Dieckman, em face de que no ano que a lei entrou em vigor, a atriz teve várias fotos íntimas divulgadas na internet, obtidas através de invasão de alguns de seus aparelhos eletrônicos pessoais, conforme notícia divulgada no site do Tribunal de Justiça de Mato Grosso.

Diante desse fato, que atingiu notoriedade nacional, deixou clara a necessidade de uma tipificação penal específica para esse tipo de crime, o que foi feito com a criação da Lei 12.737/2012, que inseriu no Código Penal, o artigo 154-A, disciplinando esta matéria, sendo o seu teor:

Invadir dispositivo informático alheio, conectado ou não à rede de computadores, mediante violação indevida de mecanismo de segurança e com o fim de obter, adulterar ou destruir dados ou informações sem autorização expressa ou tácita do titular do dispositivo ou instalar vulnerabilidades para obter vantagem ilícita.

Pena - detenção, de 3 (três) meses a 1 (um) ano, e multa. (BRASIL, 2018).

O Marco Civil da Internet foi a grande revolução que ocorreu em nosso país na relação entre direito e internet, foi a primeira legislação específica criada para disciplinar essa matéria, abrangendo vários aspectos que estavam omissos anteriormente nas normas existentes, 
estabelecendo um caminho para ser seguido pelos aplicadores do direito nos conflitos resultantes da informatização de nosso país.

\section{O "Marco Civil da Internet" no Brasil, como se sabe, é a Lei que regula o uso da Internet no Brasil, por meio da previsão de princípios e estabelecimento de garantias aos usuários. O texto trata de temas como neutralidade da rede, privacidade e retenção de dados, imponto obrigações para os provedores de serviços de internet. (TEIXEIRA, s/n, 2016).}

A iniciativa da criação do Marco Civil da Internet no ano de 2009, também chamada de Constituição da Internet Brasileira, se deu em face da divulgação de atos de espionagem por meios eletrônicos feitos, pelo governo dos Estados Unidos da América, tanto no Brasil como em outros países, assim, foi percebida a urgência do tema.

Os princípios que norteiam esta lei são a neutralidade, a privacidade e o registro de acessos. O primeiro seria a proibição da venda de pacotes e planos de internet, limitados pelo conteúdo ou origem do que se quer acessar ou usufruir, ou com preferência de um conteúdo sobre outro em decorrência do valor pago. (BRASIL, 2018).

A privacidade que é mencionada nesta lei, segue as diretrizes já estabelecidas e garantidas pela Constituição Federal, onde é considerada um dos direitos fundamentais, apenas tendo uma legislação expressa sobre a privacidade das informações, com foco na internet. E os registros de acesso diz respeito aos rastros que são deixados quando alguém acessa a rede, sendo seu armazenamento de responsabilidade dos provedores do serviço, pelo prazo mínimo de um ano. (BRASIL, 2018).

Além das informações aqui mencionadas, o Marco Civil disciplinou uma infinidade de tópicos sobre a internet em nosso país, que é praticamente impossível serem abordados, de maneira precisa, em um estudo de poucas páginas, em que não é o foco principal, todavia, com o exposto ficou clara a importância que a criação desta legislação tem em nosso ordenamento.

Criar uma agência reguladora da internet no Brasil é uma tarefa muito difícil, a melhor solução é o que se está tentando fazer, que é estabelecer normas por meio de leis, todavia, haverá, ainda, inúmeras lacunas que serão notadas quando feito a aplicação das leis existentes, e a grande dificuldade que existe é a fiscalização com relação às normas estabelecidas para verificar sua efetividade, algo que seria mais palpável por meio de uma agência regulatória.

\section{AS POSSIBILIDADES DE REGULAÇÃO DAS FAKE NEWS NO DIREITO BRASILEIRO}

A facilitação do acesso às tecnologias, apesar de apresentar inúmeros benefícios, e ser de extrema importância para o desenvolvimento de uma sociedade, também traz consigo alguns problemas que passam a ser enfrentados pelo direito, inclusive o brasileiro. Além de que, utilizada indevidamente, imprudentemente e equivocadamente, as tecnologias podem apresentar sérios percalços para a promoção de uma democracia efetiva.

Hoje a internet é o maior meio de divulgação de notícias existente, estando à frente da mídia impressa, do rádio e da televisão, sendo que qualquer um, sem uma fonte confiável, pode escrever algo e espalhar na rede e, em várias vezes, a mentira é tão bem elaborada que muitos acreditam nela, sendo até a fonte de informação inventada.

Cabe esclarecer que a mentira, a invenção, a informação manipulada ou malintencionada, sempre fez parte da sociedade, porém, o que mudou foi a maneira e a velocidade como se espalham, e diante disso, os efeitos que passam a exercer na sociedade e na democracia de um Estado. 
Conforme pontua D’Ancona (2017, p. 19), entramos em um novo panorama onde os combates políticos e intelectuais estão enfraquecendo a democracia e as ortodoxias diante de uma nova face de um populismo ameaçador. A emoção é colocada acima da razão, a diversidade fica em segundo plano para o nativismo, e a liberdade é substituída por um movimento em busca da autocracia. A política deixou de ser uma exposição de ideias e de propostas, para dar lugar a algo que não soma mais nada para o fortalecimento da democracia. A ciência, que já salvou tantas vidas, realizou tantas descobertas e sempre teve grande relevância, começou a sofrer com suspeitas, e até ser desprezada, sendo contraposta por ideias esdrúxulas.

A mentira sempre existiu, porém, o que mudou com o acesso massivo da população às tecnologias derivadas da internet, como redes sociais, aplicativos de mensagens, portais de notícias eletrônicos e outros, foi a velocidade com que as informações se propagam, tanto as verídicas e pertinentes para a promoção da democracia, tanto quanto as enganosas ou manipuladas.

Para propiciar o melhor entendimento dos apontamentos, que serão realizados nesta pesquisa, obviamente se torna necessário estabelecer os conceitos que serão aplicados para o principal objeto do estudo, ou seja, as fake news, que podem ser entendidas como "notícias falsas, em que as falsidades aparecem por intenção deliberada, e não por acidente ou erro."7 (LEVINSON, 2017, p. 11). Outra definição plausível seria de que são "notícias intencionalmente e comprovadamente falsas, podendo enganar os leitores"8. (ALLCOTT; GENTZKOW, 2017, p. 213-214).

Esse tema, inicialmente, entrou em evidência nos Estados Unidos com as eleições presidenciais americanas no ano de 2016, onde se elegeu Donald Trump. Este pleito ficou extremamente marcado por polêmicas sobre fake news, tanto do lado do presidente eleito, quanto da sua adversária Hilary Clinton.

Segundo informações divulgadas no portal eletrônico do jornal BBC Brasil, um dos maiores escândalos que surgiram nesse período seria a influência de veículos de comunicação russos, principalmente utilizando-se de programas que enviavam mensagens automáticas por meio de perfis genéricos ou até falsos, disseminando fake news, com o intuito de tentar manipular os resultados das eleições americanas. Os meios mais utilizados e que atingiam maior alcance eram as redes sociais Twitter e Facebook, além do mecanismo de pesquisa do Google ${ }^{9}$.

É interessante apresentar uma definição mais ampla. Gross (2018, p. 157), explica que as fake news são uma espécie de novo conteúdo que é produzido intencionalmente em decorrência do modelo de produção, disseminação e consumo de conteúdo online. No caso, fornece para aqueles que acessam a rede, o que eles querem ler, mesmo que a informação não seja verdadeira, levando os produtores do conteúdo falso a atingir os objetivos almejados, normalmente políticos ou financeiros.

Gross (2018, p. 157) complementa afirmando que o objetivo principal da produção desses conteúdos é explorar as circunstâncias que existem no universo online, que seriam o anonimato, a rapidez com que a informação pode ser disseminada, as fontes de informação fragmentadas e de difícil verificação, além da atenção que consegue obter dos usuários da internet, apelando ao lado emocional e ao sensacionalismo.

Ainda em consonância com a autora supracitada, os principais fins que são visados pelos criadores e/ou divulgadores das fake news são obter vantagens financeiras e ou políticas com o seu auxiílio, como exemplo, cita o caso de jovens que viviam na Macedônia, que perceberam a possibilidade de auferir lucros financeiros com a viralização de notícias falsas com relação

7 Tradução livre.

8 Tradução livre.

9 Notícia completa em: SENRA, Ricardo. Candidatos brasileiros poderão ser punidos se usarem robôs para 'fake news' em 2018. Publicada em 6 de novembro de 2017. Disponível em: https://www.bbc.com/portuguese/brasil-41881703. Acesso em 15 de janeiro de 2019. 
à política norte-americana, não tendo interesse nenhum no resultado final, mas apenas na quantidade de acesso obtidos que poderiam reverter em valores monetários para eles.

A exposição mais complexa do que é fake news é extremamente importante, pois, como coloca Rais (2018, p. 106), traduzir literalmente as fake news como notícias falsas, não resolve o problema no campo jurídico, considerando que a mentira não é um objeto central do direito. Diante disso, se apresenta a relevância dessa pesquisa, em tentar trazer uma definição útil para ser utilizada nos conflitos levados ao judiciário, principalmente.

Outro apontamento interessante realizado por Rais (2018, p. 107) é: "A polissemia aplicada à expressão fake news confunde ainda mais o seu sentido e alcance, ora indicada como se fosse uma notícia falsa, ora como se fosse uma notícia fraudulenta, ora como se fosse uma reportagem deficiente ou parcial, ou, ainda, uma agressão a alguém ou a alguma ideologia."

As fake news ferem alguns dos direitos que são garantidos pela nossa legislação, como a honra e o direito à privacidade, diante disso, tal apontamento nos leva a um debate interessante: em que hipótese um possível controle sobre as notícias que venham a ser vinculadas na internet, feriria o direito à liberdade de expressão ou o direito da população à informação?

A dificuldade em estabelecer uma regulação sobre as fake news ,surge no momento em que é difícil separar, com exatidão, o que são realmente notícias falsas, sem embasamento algum, de opiniões próprias, interpretações, em alguns casos, até há confusão com notícias verídicas, mas colocadas de uma forma duvidosa ou com a intenção de influenciar o leitor, além das sátiras, paródias, teorias da conspiração.

Uma questão que precisa ser mencionada, é que existe uma diferença entre os conceitos de fake news e de desinformação, que precisarão ser levados em consideração, uma vez que ocorrem inúmeras confusões entre ambos. Conforme Rais (2018, p. 150), um relatório produzido pelo High Level Group -HLEG (Grupo independente de Alto Nível sobre as notícias falsas e a desinformação online) da União Europeia, definiu desinformação como sendo "todas as formas de informações falsas, imprecisas ou enganadoras criadas, apresentadas e promovidas para causar prejuízo de maneira proposital ou para fins lucrativos".

No caso, o que se entende da definição acima, é que as fake news estão inseridas dentro da ideia da desinformação, todavia, não são seu único componente, se levando em conta que uma notícia, realmente verdadeira, com fontes confiáveis, dependendo do espaço ou tempo que seja compartilhada, pode adotar uma conotação diferente do seu intento inicial, ou certos trechos de falas de uma pessoa, podem ser recolocados de um forma prejudicial à sua imagem quando mudados de contexto.

Ainda, as sátiras, brincadeiras e os famigerados memes ${ }^{10}$; podem ser compartilhados com o objetivo de ludibriar quem as lê, e por alguns, o compartilhamento ocorre por simples desconhecimento e falta de análise.

A pós-verdade é outra definição que precisa ser apresentada para evitar confusões com relação a definição de fake news, conforme D’Ancona (2018, p. 20), o Oxford Dictionaries escolheu este termo como a palavra do ano de 2016, definindo-a como a "circunstância em que os fatos objetivos são menos influentes em formar a opinião pública do que os apelos à emoção e à crença pessoal."

Retornando mais especificamente para o objeto central desta pesquisa, outros exemplos de fake news, de grandes proporções e reconhecidos mundialmente, ocorridos nos Estados Unidos, preponderantemente no período eleitoral de 2016 foram a afirmação de que Obama tinha proibido o juramento de lealdade à bandeira nas escolas; de que o Papa Francisco estaria apoiando Donald Trump nas eleições; espalhou-se, também, que Trump estaria oferecendo

10 O termo é bastante conhecido e utilizado no "mundo da internet", referindo-se ao fenômeno de "viralização" de uma informação, ou seja, qualquer vídeo, imagem, frase, ideia, música e etc, que se espalhe entre vários usuários rapidamente, alcançando muita popularidade. Significado de Meme Disponível em: https://www.significados.com.br/meme/. Acesso em: o6 de fevereiro de 2019. 
passagens somente de ida gratuitas para a África e o México para aqueles que não quisessem permanecer nos Estados Unidos; e de que o Líder do Estado Islâmico teria pedido aos cidadãos norte-americanos para que votassem em Hilary Clinton. (D’ANCONA, 2018, p. 55).

No Brasil, nas eleições presidenciais, que ocorreram no ano de 2018 , houve uma onda de fake news, que fez parte do período eleitoral, onde muitas informações foram manipuladas ou aumentadas, com o intuito de causar prejuízos para os principais candidatos que disputavam o pleito, pois, "as pessoas estão muito expostas às afirmações falsas que constroem uma 'ilusão de verdade', em que uma informação imprecisa se torna mais familiar e ao longo do tempo, pode ser vista como verdade." (SPINELLI; SANTOS, p. 770, 2018).

Imaginando o que estava por ocorrer, foram feitas algumas tentativas para tentar penalizar criminalmente a divulgação de notícias falsas, já até sendo realizado um projeto de lei que não obteve aprovação até este momento (Projeto de Lei do Senado $n^{\circ} 473$, de 2017). Todavia, não foi aprovado até o momento das eleições presidenciais, deixando assim, vários dilemas para a resolução do poder judiciário.

Porém, é possível compreender porque não houve a aprovação de tal projeto, considerando todas as problemáticas que se apresentam para estabelecer uma regulação sobre as fake news, levando em conta que vários outros direitos fundamentais, como o direito à liberdade de expressão, acabam entrando em conflito, podendo, numa definição equivocada ou imprecisa, criar inúmeros dilemas para o direito brasileiro.

Um dos meios mais eficientes para combater a propagação das fake news, são as chamadas agências de fact-chaking, ou na tradução mais próxima, as agências de checagem de fatos. Seu objetivo é verificar as fontes das notícias, a veracidade dos fatos apresentados e, também, em menor escala, se não houve manipulação em como é informado os acontecimentos. Essa prática já é comum em vários outros países, e há pouco tempo, chegou com força no nosso país. (SPINELLI; SANTOS, 2018).

"No Brasil, três agências são certificadas pelo IFCN (International Factchecking Network): Lupa, Truco e Aos Fatos. As instituições credenciadas devem estabelecer compromissos com apartidarismo e equidade, transparência das fontes e de financiamento da organização, detalhes sobre métodos utilizados e correções francas e amplas." (SPINELLI; SANTOS, 2018, p. 771).

Vários veículos de comunicação, de alcance nacional, utilizam dos serviços prestados por essa agência, como a revista Época, os jornais Folhas de São Paulo e O Globo, o canal de notícias Globo News, a UOL, Buzzfedd e vários outros, em consonância com o informado por Spinelli e Santos (2018). Sobre o modo de operação das agências de fact-chaking, cabe ressaltar:

O que faz do fact-checking uma prática relevante ao jornalismo na era da pós-verdade é a preocupação com a transparência e credibilidade. Os métodos de checagem não mudam muito entre as agências, mas todas explicam como chegaram à conclusão sobre a veracidade das informações publicadas, destacando as fontes originais de informação com links e referências. Outro ponto importante para assegurar a qualidade é a busca pela diversidade de personalidades checadas e uma política clara de erros. As agências não checam opiniões e previsões, além de tópicos de pouca relevância para o debate público, como vícios de linguagem, questões de foro íntimo e afins. Assim como as demais plataformas verificadas pela IFCN a partir de seu código de boas práticas, os métodos de checagem são públicos. (SPINELLI; SANTOS, 2018, p. 773).

Esse é um dos meios mais eficientes para combater essa prática maléfica para a sociedade, porém não há como penalizar aquele que inventou a notícia falsa e sendo ainda mais difícil, impor sanções para aqueles que somente compartilharam, considerando que 
não existe uma legislação vigente específica sobre a matéria no Brasil, além da dificuldade de torná-la efetiva caso passasse a existir.

Existem algumas possibilidades para tentar amenizar essa disseminação em massa de fake-news no Brasil, todas usando do conceito aplicado pelas agências de fact-chaking, talvez sendo possível a criação de uma agência reguladora das fake news pelo próprio governo, ou um apoio do governo para as agências de fact-chaking para um trabalho em conjunto, ou então, tentar estabelecer normas específicas para esse tema por meio de lei.

O que não pode se manter, é incumbir o do Poder Judiciário de resolver os conflitos suscitados, sem uma legislação para se embasar, como foi com as demandas que envolviam a internet no passado. Não há como resolver todos os conflitos perfeitamente, com base em analogias e princípios, sem que venham a existir divergências entre os tribunais existentes no território brasileiro, podendo implicar, na pior das hipoétese, em algumas decisões, até a prática do ativismono pelos magistrados, diante da omissão do poder legislativo.

A liberdade de expressão e o direito à informação são dois dos direitos garantidos pela Constituição, assim é preciso conseguir estabelecer um limite entre a garantia desses direitos e a repressão contra as fake news. Sobre isso, vale apresentar a seguinte reflexão que demonstra a análise que deve ser feita pelos legisladores e aplicadores do direito sobre as fake news:

\begin{abstract}
A liberdade de expressão não é um direito absoluto, nem ilimitado. Nenhum direito fundamental o é. Como diria Justice Oliver Wendell Holmes, a liberdade de expressão não protege alguém que grite "fogo!" falsamente no interior de um teatro lotado. Assim, em caso de conflito, ela poderá, eventualmente, ceder lugar em favor de outros bens e valores constitucionalmente protegidos. (KOATZ, 2011, p. 401).
\end{abstract}

Diante do comentário acima, fica perceptível a existência de uma linha tênue entre o combate as fake news e o direito à liberdade de expressão, que é um dos maiores dilemas existente nessas demandas, uma vez que o direito de proibir a divulgação de certos conteúdos, sites, matérias e afins, com o intuito de evitar a proliferação de fake news, em determinadas situações pode vir a invadir o direito à liberdade de expressão.

Assim, a criação de uma agência reguladora de fake news, poderia levar à uma melhor preparação do governo para lidar com essa temática, talvez com o auxílio das agências de factchaking, ou o próprio Estado passando a agir como fiscalizador. para conseguir estabelecer o que é uma informação sem fundamento de uma simples opinião ou exposição é um dos dilemas a ser enfrentados.

Um bom exemplo de atuação do Estado no combate as fake news já realizado, é na área da saúde, onde, seja com intenção maliciosa, ou simplesmente diante da confusão com os costumes e os hábitos populares são propagadas informações falsas sobre curas, tratamentos, doenças e afins. O nível de preocupação que atingiu este tipo de atitude, levou o Ministério da Saúde do Brasil a criar uma seção, em seu site ${ }^{12}$, especificamente para verificar e analisar a veracidade das notícias divulgadas, tanto nas redes sociais, quanto em portais de notícias.

Alguns bons exemplos que são apresentados no site, os quais foram identificadas como informações falsas, são com relação a vacinas que causam autismo, sobre a possibilidade do chá de graviolas curar o câncer, o comprimido de Paracetamol que contém o vírus Machupo e inúmeras outras afirmações desmentidas, a partir de fatos verídicos expostos pelo Ministério da Saúde, publicamente.

11 O ativismo judicial é "um fenômeno pós-moderno caracterizado pela forte atuação do Poder Judiciário nas relações sociais, de forma a regular políticas públicas e intervir em aspectos da vida privada dos indivíduos”. (CARMO; MESSIAS, p. 196, 2017).

$12 \mathrm{http}: / /$ portalms.saude.gov.br/fakenews 
A medida acima se mostra interessante, uma vez que apresenta resultados, mas atua de forma repressiva, não preventiva, o que poderia ocorrer em censura, considerando que seria possível que existisse um desrespeito ao direito à liberdade de expressão.

Costa Neto (2017, p. 37), apresenta o direito à liberdade de expressão em sua dimensão negativa, ou seja, ele a define como o "direito de expressar-se sem obstáculos ou restrições." Inclusive, aponta que os maiores obstáculos ao direito anteriormente citado, seriam "a censura, sanções penais, cíveis ou administrativas, ameaças de violência, restrições legais, queimas de livros, softwares de bloqueio de páginas na internet, etc."

O caminho que deve ser tomado para evitar o máximo possível a ocorrência de censura e da proibição da exposição de ideias pessoais, é a existência de um controle repressivo, não preventivo, pois, permitir que o Estado controle previamente todos os conteúdos que serão divulgados, seja na internet, jornal, rádio ou televisão, colocaria um poder excessivo do Estado sobre os veículos de comunicação.

O melhor meio de combater a desinformação é com informação, ou seja, Maranhão e Campos (2018, p. 218/219), expõem que qualquer mecanismo que seja por meio da exclusão ou retirada de conteúdo ou perfis pode afetar o direito à liberdade de expressão, então, o melhor caminho deve ser combater os males causados pela divulgação fraudulenta, com informações verídicas e esclarecer os fatos para os usuários que acessarem a falsa notícia.

Conforme apontam os autores acima, o ideal é que o próprio conteúdo lesivo, após verificada a sua falsidade, indique o conteúdo esclarecedor de forma destacada, indicando ao leitor as informações verdadeiras e desmentindo os dados errôneos. Esta medida funcionaria perfeitamente em portais eletrônicos e redes sociais, sendo o caminho mais adequado.

Além dos apontamentos realizados acima, outra questão relevante é com relação a definição do como devem ser compreendidas as fake news, devendo ficar claro como devem ser interpretadas pelos tribunais para evitar a ocorrência de insegurança jurídica.

No melhor dos cenários, essa definição não deve ser deixada para ser resolvida quando o conflito estiver chegado ao poder judiciário, o ideal seria que já existissem parâmetros anteriores para analisar estas demandas, não ficando a critério do magistrado as definições técnicas, ou seja, definir se é verídica ou não a informação, bem como se as fontes são confiáveis ou são ficcionais.

\section{CONSIDERAÇÕES FINAIS}

Não é uma tarefa simples conseguir estabelecer um controle sobre as fake news no atual cenário do direito brasileiro, diante da imensidão que é a internet, onde muitas vezes é dificílimo encontrar vestígios de quem foi o criador ou daqueles que compartilharam, até pela grande proporção que a propagação dessas informações sem fundamentos ou distorcidas podem atingir.

Esse é um fato novo que merece a atenção do direito brasileiro diante da sua relevância e dos conflitos e influências que pode causar na nossa sociedade. Algumas medidas foram propostas pelas câmaras federais do poder legislativo de nosso país, porém ainda contém omissões e obscuridades sobre essa matéria, mas já seria um inicio para tentar regular esse tema, haja vista que não há nada especifico sobre.

No cenário atual, a regulação por meio da legislação é o caminho mais palpável, todavia é de difícil fiscalização e execução, onde talvez, a possibilidade da criação de uma agência reguladora cumpriria melhor a tarefa, mesmo diante das dificuldades existentes, ou como alternativa, seria o apoio do Estado para as agências de fact-chaking já estabelecidas, como 
uma forma de evitar danos decorrentes das fake news, as quais já se demostraram prejudiciais tanto para a política, democracia e até à saúde.

Considerando que a problemática apresentada ao inicio desta pesquisa foi respondida da melhor forma possível, e que o objetivo geral, bem como os específicos foram cumpridos, além da hipótese ter sido confirmada, uma vez que denota-se que observados certos requisitos, a regulação do Estado sobre as fake news, principalmente de forma repressiva, é a melhor medida para combater os males que dela decorrem.

\section{REFERÊNCIAS}

ALLCOTT, Hunt; GENTZKOW, Matthew. Social Media and Fake news in the 2016 Election. Journal of Economic Perspectives, Volume 31, Número. 2, 2017, Pág. 211-236. Disponível em: https://www.aeaweb.org/articles?id=10.1257/jep.31.2.211. Acesso em: 31 de janeiro de 2019.

BRASIL. Constituição da República Federativa do Brasil de 1988. Disponível em: http:// www.planalto.gov.br/ccivil_03/constituicao/constituicaocompilado.htm. Acesso em: 06 de janeiro de 2019.

BRASIL. Lei no 12.737, de 30 de novembro de 2012. Dispõe sobre a tipificação criminal de delitos informáticos; altera o Decreto-Lei no 2.848, de 7 de dezembro de 1940 - Código Penal; e dá outras Providências. Disponível em: http://www.planalto.gov.br/ccivil_03/_ato2011-2014/2012/ lei/l12737.htm. Acesso em: 25/o7/2018.

BRASIL. Lei no 12.965, de 23 de abril de 2014. Estabelece princípios, garantias, direitos e deveres para o uso da Internet no Brasil. Disponível em: http://www.planalto.gov.br/ccivil_03/_ ato2011-2014/2014/lei/l12965.htm. Acesso em: 21 de janeiro de 2019.

BRASIL. Lei no 13.709, de 14 de agosto de 2018. Dispõe sobre a proteção de dados pessoais e altera a Lei no 12.965, de 23 de abril de 2014 (Marco Civil da Internet). Disponível em: http:// www.planalto.gov.br/ccivil_03/_ato2015- 2018/2018/lei/L13709.htm. Acesso em: 22 de janeiro de 2019 .

BRASIL. Veto parcial da Lei 13.709, de 14 de Agosto de 2018. Dispõe sobre a proteção de dados pessoais e altera a Lei no 12.965, de 23 de abril de 2014 (Marco Civil da Internet). Disponível em: http://www2.camara.leg.br/legin/fed/lei/2018/lei-13709-14-agosto-2018-787077-veto-156214-pl. html. Acesso em: 22 de janeiro de 2019.

CARMO, Valter Moura do; MESSIAS, Ewerton Ricardo. Pós-modernidade e principiologia jurídica: $\mathrm{O}$ ativismo judicial e sua validade no âmbito do Estado Democrático de Direito. Revista Brasileira de Direito, Passo Fundo, vol. 13, n. 3, p. 189-205, Set.-Dez., 2017. Disponível em: https://seer.imed.edu.br/index.php/revistadedireito/article/view/2163/1404. Acesso em o6 de janeiro de 2019 .

COSTA NETO, João. Liberdade Expressão: o conflito entre e o legislador e o juiz constitucional. São Paulo: Saraiva, 2017. 
D'ANCONA, Matthew. Pós-verdade: A nova guerra contra os fatos em tempos de Fake news. Tradução: Varlos Szlak. 1. Ed. Barueri: Faro Editorial, 2018.

FORTES, Vinícius Borges. Os direitos de privacidade e a proteção de dados pessoais na internet. Editora Lumen Juris, Rio de Janeiro, 2016.

GOVERNO DO BRASIL. Agências reguladoras fiscalizam a prestação de serviços públicos. Disponível em: http://www.brasil.gov.br/governo/2009/11/agencias-reguladoras. Acesso em: o3 de janeiro de 2019.

GROSS, Clarissa Piterman. Fake news e Democracia: Discutindo o status normativo do falso e a liberdade de expressão. In: Fake news: a conexão entre a desinformação e o direito. Coordenador: Diogo Rais. São Paulo: Thomson Reuters Brasil, 2018.

GROTTI, Dinorá Adelaide Musetti. Agências Reguladoras. Revista da Faculdade de Direito de São Bernardo do Campo. Capa, v. 10. 2004. Disponível em: https://revistas.direitosbc.br/ index.php/fdsbc/article/view/398/265 Acesso em:31/07/2018.

GUERRA, Sérgio. Regulação estatal sob a ótica da organização administrativa brasileira. In: Regulação no Brasil: uma visão multidisciplinar / Org. Sérgio Guerra. - Rio de Janeiro: Editora FGV, 2014.

INSTITUTO BRASILEIRO DE DEFESA DO CONSUMIDOR. Defesa do consumidor, participação social e ferramentas para a cidadania: Um banco de dados para o monitoramento da regulação. São Paulo: IDEC, 2011. Disponível em: https://idec.org.br/ file/22486/download?token=SSVXpCj6. Acesso em: 31 de janeiro de 2019.

KOATZ, Rafael Lorenzo- Fernandez. As liberdades de expressão e de imprensa da jurisprudência do STF. In: D. SARMENTO; I.W. SARLET, Direitos fundamentais no Supremo Tribunal Federal: balanço e crítica. Rio de Janeiro, Lumen Juris. 2011. Disponível em:https:// www.academia.edu/16893547/As_liberdades_de_express\%C3\%A30_e_de_imprensa_na_ jurisprud\%C3\%AAncia_do_Supremo_Tribunal_Federal. Acesso em: 31 de janeiro de 2019.

LEAL, Carlos Ivan Simonsen. Prefácio. In: Regulação no Brasil: uma visão multidisciplinar / Org. Sérgio Guerra. - Rio de Janeiro: Editora FGV, 2014.

LEVINSON, Paul. Fake news in real context. Connected Editions. Edição do Kindle, 2017.

MARANHÃO, Juliano; CAMPOS, Ricardo. Fake news e autorregulação regulada das redes sociais no Brasil: fundamentos constitucionais. In: Fake news e Regulação. Coordenadores: Georges Abboud; Nelson Nery Jr. e Ricardo Campos. São Paulo: Thomson Reuters Brasil, 2018.

MELLO, Celso Antônio Bandeira de. Curso de Direito Administrativo. São Paulo: Malheiros, 2013.

MORAES, Alexandre de. Reforma Administrativa: Emenda Constitucional no 19/98. 3 . ed., São Paulo: Atlas, 1999. 
NETO, Floriano de Azevedo Marques. A nova regulação dos serviços públicos. Revista Direito Administrativo. Rio De Janeiro. 2002. Disponível em: http://bibliotecadigital.fgv.br/ ojs/index.php/rda/article/view/46521. Acesso em: 31 de janeiro de 2019

OLIVEIRA, Rafael Santos de; BARROS, Bruno Mello Corrêa de; GOULART, Gil Monteiro. As tecnologias da informação e comunicação na (des)construção das relações humanas contemporâneas: implicações do uso do aplicativo Tinder. Revista Brasileira de Direito, pág. 88-99, jan.-jun. 2016. Disponível em: https://seer.imed.edu.br/index.php/revistadedireito/ article/view/919/840. Acesso em: 31 de janeiro de 2019.

PECI, Alketa. Regulação e Administração Pública. In: Regulação no Brasil: uma visão multidisciplinar / Org. Sérgio Guerra. - Rio de Janeiro: Editora FGV, 2014.

RAIS, Diogo. Desinformação no contexto democrático. In: Fake news e Regulação. Coordenadores: Georges Abboud; Nelson Nery Jr. e Ricardo Campos. São Paulo: Thomson Reuters Brasil, 2018.

RAIS, Diogo. Fake news e Eleições. In: Fake news: a conexão entre a desinformação e o direito. Coordenador: Diogo Rais. São Paulo: Thomson Reuters Brasil, 2018.

SAMPAIO. Patrícia Regina. Regulação da atividade de petróleo e do gás natural no Brasil. In: Regulação no Brasil: uma visão multidisciplinar / Org. Sérgio Guerra. - Rio de Janeiro: Editora FGV, 2014.

SENADO FEDERAL. Projeto de lei no 53. Iniciativa: Deputado Federal Milton Monti (PR/SP). Disponível em: https://legis.senado.leg.br/sdleggetter/ documento?dm=7738646\&disposition=inline. Acesso em: 20 de janeiro de 2019.

SPINELLI, Egle Müller; SANTOS, Jéssica de Almeida. Jornalismo na era da Pós-verdade: fact-checking como ferramenta de combate às fake news. Revista Observatório, Palmas, v. 4, n. 3, p. 759-782, maio. 2018. Disponível em: https://sistemas.uft.edu.br/periodicos/index. php/observatorio/article/view/4629 Acesso em: 31 de janeiro de 2019.

SUNDFELD, Carlos Ari. Direito público e regulação no Brasil. In: Regulação no Brasil : uma visão multidisciplinar / Org. Sérgio Guerra. - Rio de Janeiro: Editora FGV, 2014.

TEIXEIRA, Tarcisio. Marco Civil da Internet. Editora Leya. 2016. Disponível em: https://books.google. com.br/books/about/Marco_Civil_da_Internet.html?id=JwADDAAAQBAJ\&redir_esc=y. Acesso em: 22 de janeiro de 2019 .

WALD, Arnoldo; MORAES, Luiza Rangel de. Agências reguladoras. Revista de Informação Legislativa. Brasília, a. 36, n. 141 jan./mar. 1999. Disponível em: https://www2.senado.leg.br/ bdsf/bitstream/handle/id/457/r141-12.pdf?sequence=4 Acesso em: 31 de janeiro de 2019 .

SILVA, Werner Leonardo. Internet foi criada em 1969 com o nome de "Arpanet" nos EUA. Disponível em: https://www1.folha.uol.com.br/folha/cotidiano/ult95u34809.shtml. Acesso em o4 de fevereiro de 2019. 
PRANDO, Alisson. Músicas dos Anos 6o: O Sucesso que Balançou o Mundo. Disponível em: https://www.uppermag.com/musicas-dos-anos-6o/. Acesso em: 04 de fevereiro de 2019.

NATALO, Camila. 13 cantores e bandas que foram descobertos na internet. Disponível em: http://www.popcidade.com.br/2016/o2/18/13-cantores-e-bandas-que-foram-descobertosna-internet/. Acesso em: 04 de fevereiro de 2019.

Do VHS ao streaming, conheça a evolução das tecnologias de armazenamento e compartilhamento de vídeo. Disponível em:http://www.olhardireto.com.br/noticias/ exibir.asp?id=408271\&noticia=do-vhs-ao-streaming-conheca-a-evolucao-das-tecnologias-dearmazenamento-e-compartilhamento-de-video. Acesso em: o4 de fevereiro de 2019.

SENRA, Ricardo. Candidatos brasileiros poderão ser punidos se usarem robôs para 'fake news' em 2018. Publicada em 6 de novembro de 2017. Disponível em: https://www.bbc.com/ portuguese/brasil-41881703. Acesso em 15 de janeiro de 2019.

Significado de Meme Disponível em: https://www.significados.com.br/meme/. Acesso em: o6 de fevereiro de 2019. 